\title{
Evaluating the impact of karst rocky desertification on regional climate in Southwest China with WRF
}

\author{
Weilin Yang ${ }^{1,2} \cdot$ Wenchao $\mathrm{Chu}^{2,3} \cdot$ Limin $\mathrm{Zhou}^{2}$ (1)
}

Received: 2 May 2018 / Accepted: 21 August 2018 / Published online: 31 August 2018

(C) The Author(s) 2018

\begin{abstract}
It has been confirmed that the karst rocky desertification (KRD) has severely changed the interactions between atmosphere and terrestrial ecosystem which would cause a significant effect on regional climate system. In this study, the Weather and Research Forecasting model was applied to investigate the biogeophysical impact on temperature and precipitation change by land use/land cover change data with different KRD conditions in 1993, 2003, and 2013 in Southwest China. The results showed that an improving trend of KRD has been found in Southwest China, especially in east Sichuan, Chungking, southwest Yunnan, and south Guangxi. The $2-\mathrm{m}$ air temperature decreased by $0 \sim-1{ }^{\circ} \mathrm{C}$ in general with this improving trend. The possible reason was the decreasing KRD accompanied by the decreasing albedo, causing the increasing net shortwave radiation and the increasing net radiation. Meanwhile, the increasing evaporation strengthened the latent heat flux and weakened the sensible heat flux so that decreased temperature was addressed in forest areas. The effect of KRD change transferred to the upper troposphere through atmosphere vertical convection, which made the subtropical high to be strengthened and westerly extended. Therefore, the upward moisture flux at the surface (QFX) was weakened in the central part of Guangxi, southern Guizhou, which led to the decrease of the precipitation. Moreover, the southwest monsoon was strengthened, which caused the increasing water vapor flux and led to the heavy rainfall in the west of Yunnan.
\end{abstract}

\section{Introduction}

The Southwest China $\left(20^{\circ} 54^{\prime} \sim 34^{\circ} 19^{\prime} \mathrm{N}, 97^{\circ} 21^{\prime} \sim 112^{\circ} 04^{\prime}\right.$ E), including Yunnan, Guizhou, Sichuan, Guangxi, and Chungking provinces, is regarded as a relatively complete and independent geographical area (Fig. 1). It covers about 1.37 million $\mathrm{km}^{2}$ accounting for $14.27 \%$ area of China but the karst rocky desertification (KRD) occupied $74.68 \%$ (in 2005 ) and $68.43 \%$ (in 2011) of land area of Southwest China (State Forestry Administration P.R. China 2012), which is considered as one of the largest karst geomorphology distributing areas in the world (Yan and Cai 2015). Serious soil

Limin Zhou

lmzhou@geo.ecnu.edu.cn

1 College of Urban and Environmental Sciences, Peking University, Beijing 100871, China

2 School of Geographical Sciences, Key Laboratory of Geographical Information Science of Ministry of Education, East China Normal University, Shanghai 200241, China

3 Center for Earth System Science, Tsinghua University, Beijing 100084, China erosion, extensive exposure of basement rocks, and drastic decrease of land productivity were ascribed to KRD, which has a sustainable impact on regional-global social and natural ecosystems (Li et al. 2009; Jiang et al. 2014). In addition, with plenty of studies focused on KRD problems, it began to be realized that the KRD had potential impacts on the interactions between the atmosphere and terrestrial ecosystem. The previous researches indicated that the temperature anomalies induced by land use/land cover change (LUCC) were mostly stronger than the temperature changes due to the greenhouse gas forcing (Rigden and Li 2017). And in Southwest Western Australia, Pitman et al. (2004) found that the LUCC could explain up to $50 \%$ of local warming.

To climate effect due to the KRD variation, $\mathrm{Lu}$ et al. (2015) noted that the KRD area showed a significant increase in temperature and extreme weather through a longterm trend analysis. Lian et al. (2014) found that the 5-year moving averages of the annual mean maximum and minimum temperature showed an increase but the precipitation showed no consistent increase by non-parametric MannKendall rank and the Pettitt-Mann-Whitney change point statistics analysis. However, compared with modeling, by the traditional statistical methods mentioned above, it 
Fig. 1 The Southwest China

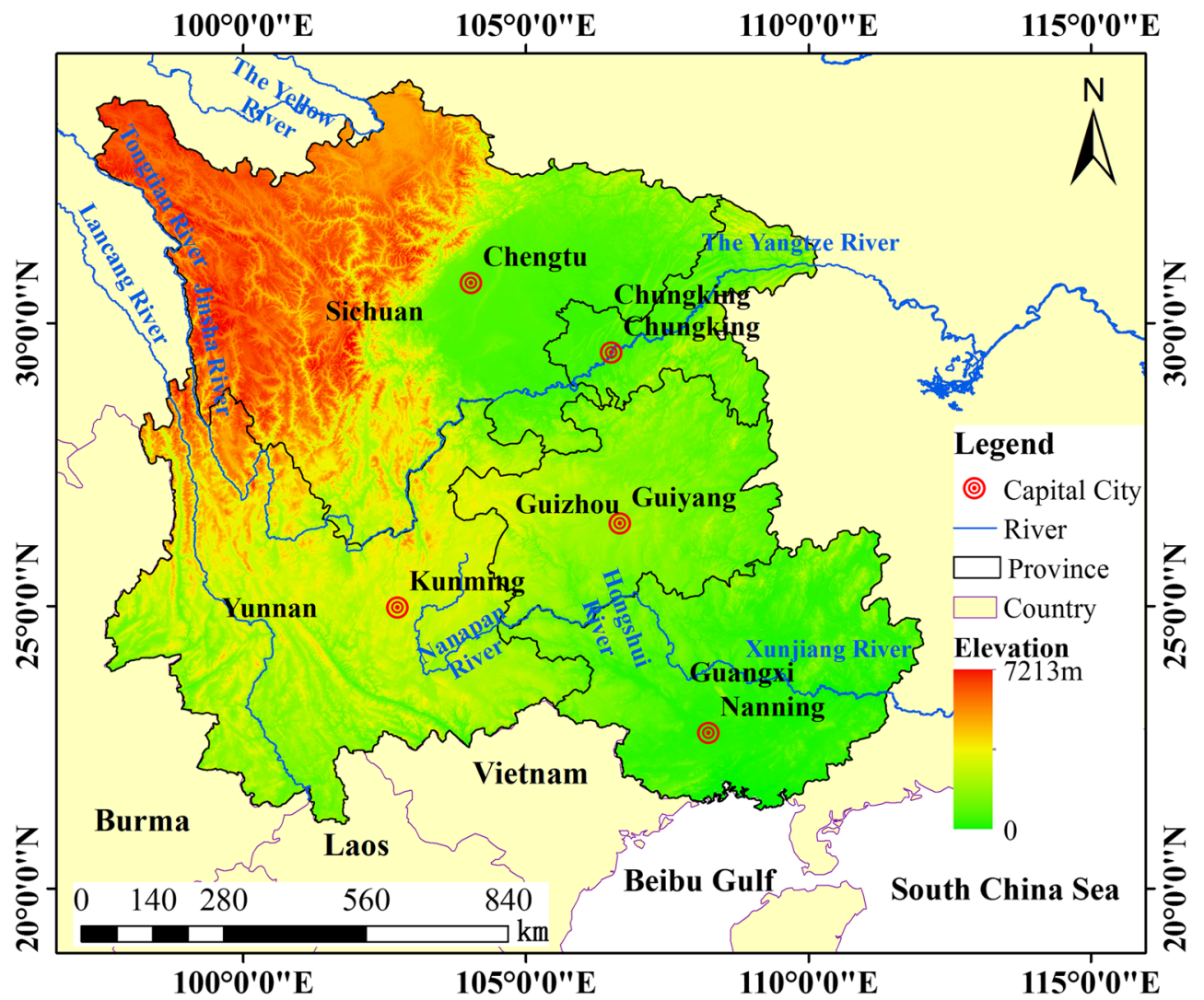

could only get the correlations between the KRD and regional climate, but the inner mechanisms that constituted land-atmosphere coupling cannot be revealed (Betts et al. 1996; Seneviratne et al. 2006; Pielke et al. 2011; Hirsch et al. 2014). Consequently, using climate model for attribution, the study has entered a new, accelerated phase (Pongratz et al. 2006; Cao et al. 2015).

The previous simulation results revealed that the terrestrial ecosystem influenced the regional climate through two major categories: biogeophysical and biogeochemical processes. The biogeochemical processes affected climate through alerting atmospheric chemical composition and the rate of biogeochemical cycles (Feddema et al. 2005). The biogeophysical processes affected the physical parameters such as surface albedo, evapotranspiration, and roughness which could influence the absorption and disposition of surface energy and water cycles and could cause either warming or cooling due to the high spatial heterogeneity ( $\mathrm{Li}$ et al. 2015; Vygodskaya et al. 2007). On the one hand, the deforestation cooled the surface by increasing surface albedo and decreasing net solar radiation (Lejeune et al. 2015). And the LUCC transitions from natural vegetation to agriculture also made the mean annual global albedo to increase which could be translated into a top-of-atmosphere radiative cooling (Ghimire et al. 2014). On the other hand, the decreasing roughness and evapotranspiration efficiency had a warming effect consisting with a lower latent heat flux but a higher sensible heat flux by deforestation (Bonan 2008; Davin and Nobletducoudré 2010). Moreover, Chen and Dirmeyer (2016) found that the surface roughness effect was the dominated factor of the direct biogeophysical feedback of LUCC, while these direct effects could be attenuated by large-scale atmospheric changes. Therefore, the temperature change was combined with both radiation and heat flux processes so that it is necessary to determine which one was the main factor in Southwest China. As for precipitation change, it was even more complex and less significant at the statistical level that the effects of LUCC change on rainfall than temperature (Pitman et al. 2012). Through cloud cover fraction, wind vector analysis, and water vapor transportation analysis, Renato et al. (2008) pointed that deforestation on the Amazon Basin progressively decreased the basinaveraged precipitation in wet season and Wang et al. (2014) confirmed that the LUCC changes in China mainly increased the precipitation in the Hetao Plain. In Southwest Western Australia, Kala et al. (2011) found that the LUCC change caused a decrease in total frontal precipitation.

Considering regional climate effect of KRD, few works focused on the biogeophysical mechanisms. Gao and $\mathrm{Wu}$ (2014) found that the temperature increased with the increasing surface albedo and the decreasing net radiation, and with the latent decreasing heat flux and the increasing sensible heat flux after changing the $\mathrm{SSiB}$ vegetation types to broadleaf 
shrubs or bare soil in the Guizhou Karst Plateau. Furthermore, land degradation in Guizhou could also weaken the southwest monsoon flow and influence the East Asian summer monsoon (Gao et al. 2013). The above conclusions have revealed part of the biogeophysical mechanisms, but using the idealized LUCC data could not reflect the real terrestrial ecosystem condition, which resulted in the bias in the energy balance and water transfer between the near-surface and atmosphere. Therefore, it may lead to misinterpretation of the KRD climate effect. In this study, real LUCC data would be used to express the KRD variation and solve above problems, based on the contact of LUCC and KRD. The KRD occurrence in different LUCC was different, while the LUCC was also different combined with the spatial distribution and intensity differences of KRD inversely (Ying et al. 2012; Ying et al. 2014; Jiang et al. 2009).

The specific research objectives were as follows: the data source and methods are discussed in Section 2. In Section 2.2.1, the KRD extraction and the spatio-temporal variation of KRD in Southwest China from 1993 to 2013 are addressed. The simulation design based on the weather and research forecasting (WRF) regional climate model and the evaluation of the performance of WRF model in temperature and precipitation are introduced in Section 2.2.2. And we compare the summer $2 \mathrm{~m}$ air temperature and precipitation simulation results of three different experiments in Section 3. In the discussion, we analyze the biogeophysical processes of temperature and precipitation and compare the results with previous studies. Finally, we make the conclusion in Section 5.

\section{Data and methods}

\subsection{Data source}

The AVHRR GIMMS Normalized Different Vegetation Index (NDVI) 15 days data with pixel size $8 \mathrm{~km} \times 8 \mathrm{~km}$ from 1993 to 2006 were from WestDC (https://westdc.westgis.ac.cn/). The original data has already managed for radiation, geometry, and atmospheric correction (Tucker et al. 2004). The atmospheric and radiative geometry corrections were done by a monthly maximum value composition (MVC) (Pinzón et al. 2005). The MODND1M China 500M NDVI Monthly Synthetic Product from 2001 to 2013 was provided by Geospatial Data Cloud (https://www.gscloud.cn). Based on pixel-by-pixel time series principle, the AVHRR NDVI data from 1993 to 2000 was corrected by variance regression analysis within AVHRR and MODIS NDVI in 2001 2006 to minimize the difference between the two NDVI data sets. The yearly MVC was adapted to get the yearly NDVI condition for KRD extraction.
The LUCC data from 1993 to 1997 was WRF 1993 USGS LUCC classification. The MODIS MCD_12Q1 LUCC data with a spatial resolution of $250 \mathrm{~m} \times 250 \mathrm{~m}$ from 2001 to 2013 was available at NASA (https://modis.gsfc.nasa.gov/data/). The LUCC data from 1998 to 2001 was replaced by the MCD 12Q1 LUCC data in 2001. We used the LUCC data from 1993 to 2013 for further KRD index correction and the LUCC data in 1993, 2003, and 2013 in the simulation part.

The National Centers for Environmental Prediction (NECP) meteorological field data with a 6-h time interval was used as the initial field and the lateral boundary forcing. The daily measured temperature and precipitation data in June, 2013, was from China Meteorological Data Service Center (CMDC) V3.0 (http://data.cma.cn/site/index.html).

\subsection{Methods}

\subsubsection{KRD extraction}

The vegetation coverage rate and exposed rock rate were calculated based on NDVI Dimidiate Pixel Model (format 1) with the yearly NDVI data. The LUCC data was used to correct the extraction results by removing the water area and the urban built-up area. The classification standard of KRD is shown in Table 1. Specially, we compared the spatiotemporal change of KRD in years 1993, 2003, and 2013 to investigate the impact of KRD on regional climate. Furthermore, the vegetation coverage index was averaged to reflect the trend and mutation of KRD during the 21 years in Southwest China.

$f_{i, j}=\frac{\mathrm{NDVI}_{i, j}-\mathrm{NDVI}_{\text {soil }}}{\mathrm{NDVI}_{\mathrm{veg}}-\mathrm{NDVI}_{\text {soil }}}$

where $\mathrm{NDVI}_{\text {soil }}$ referred to the bare soil NDVI and the $\mathrm{NDVI}_{\mathrm{veg}}$ was the dense vegetation NDVI. In this study, we defined the $\mathrm{NDVI}_{\text {soil }}$ and $\mathrm{NDVI}_{\text {veg }}$ as the lower and upper $5 \%$.

In Mann-Kendall mutation testing (Fig. 2a), the intersection point of UF statistics line and UB statistics line was $(2004,2.773)$ and 2.773 was not in the range of -1.96 to 1.96, meaning an insignificance. The UF statistics line was higher than the upper criterion value (1.96) since 2004,

Table 1 The classification standard of KRD (DD2004-02 Regional Environmental Geological Survey General (Trial))

\begin{tabular}{lll}
\hline Class & Percentage of exposed rock & Percentage of vegetation \\
\hline Very severely & $>70 \%$ & $<30 \%$ \\
Severely & $50 \sim 70 \%$ & $30 \sim 50 \%$ \\
Moderately & $30 \sim 50 \%$ & $50 \sim 70 \%$ \\
Slightly & $10 \sim 30 \%$ & $70 \sim 90 \%$ \\
Non-rock & $<10 \%$ & $>90 \%$ \\
\hline
\end{tabular}



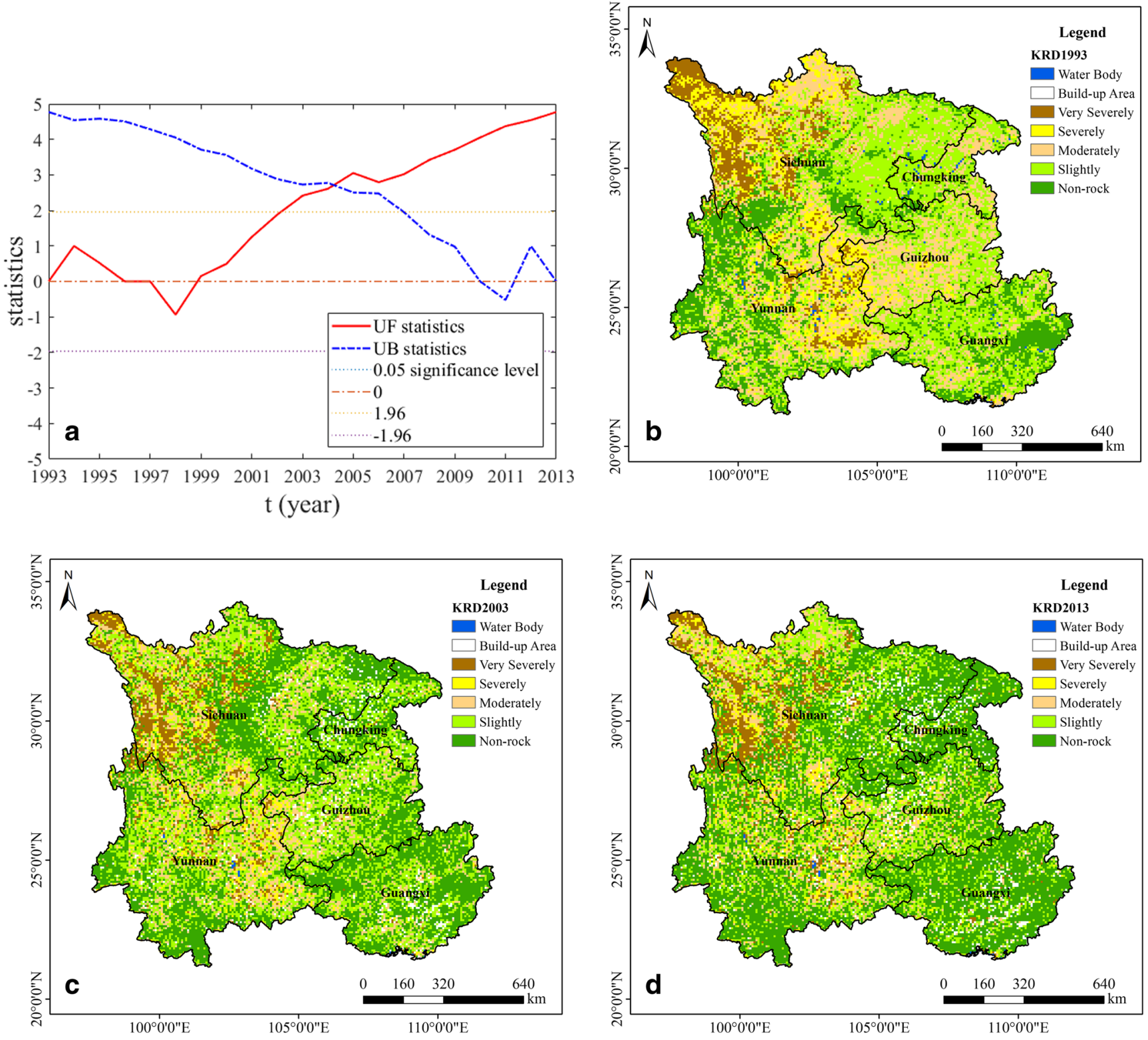

Fig. 2 a The results of Mann-Kendall mutation test. b-d The classification of rocky desertification in 1993 (b), 2003 (c), and 2013 (d)

indicating that the vegetation coverage had an obvious recovering trend. Therefore, the KRD in Southwest China had an improving trend during 1993 to 2013 and did not mutate at that time period.

The spatial distribution of five KRD classes in 1993, 2003, and 2013 is illustrated in Fig. 2b-d, showing that (1) the nonrock area took an obvious increase, covering $19.34 \%$ in 1993, $37.44 \%$ in 2003 , and $47.67 \%$ in 2013 of the total area in Southwest China. And the increased areas were mainly in south Guangxi, southwest Yunnan, and Sichuan basin. (2) Compared with the KRD condition in 1993, the slightly KRD took an extreme decrease by $3.2 \%$ in 2003 and $11.89 \%$ in 2013, lying in the most areas in Guangxi, Chungking7, and east Sichuan. (3) The moderately KRD also had a decrease during the 21 years, accounting for $25.49 \%$ in $1993,15.10 \%$ in 2003 , and $12.75 \%$ in 2013 , respectively. These areas were in Guizhou and the east of Chungking. (4) The severely KRD was occupied $11.89 \%$ in $1993,5.95 \%$ in 2003 and 5.95\% in 2013. (5) The very severely KRD which was exposed bare rocks composed less than $8 \%$ of the land about $7.88 \%$ in 1993 and $6.47 \%$ in 2003 and 2013, respectively.

\subsubsection{Simulation experiments design}

Three independent experiments were designed to investigate the impacts of KRD on regional climate based on WRF version 3.7 model. All three experiments were given the same initial 
condition, lateral condition (2012-12-30 00:00:00 2014-01-01 00:00:00 NECP meteorological field data) and parameterization schemes but different in the LUCC static data (Table 2). Exp1 and Exp2 used USGS LUCC data in 1993 and IGBP MODIS_MCD12Q1 LUCC data in 2003 separately and were considered as the sensible tests. Exp3 used the IGBP MODIS_MCD12Q1 LUCC data in 2013 and was considered as the control run. Due to different parameterization schemes adaptable to different regions, we chose the schemes mainly based on the previous studies. Single-moment three-class (WSM3) microphysics scheme, the Kain-Fritsch (KF) cumulus scheme, and the Yonsei University planetary boundary layer (YSU) scheme were selected in our study according to Gao et al. (2013) and Gao and $\mathrm{Wu}$ (2014). The first domain was centered at $29.917^{\circ} \mathrm{N}, 100.505^{\circ} \mathrm{E}$ on a Lambert projection with a spatial resolution of $60 \mathrm{~km}$ (about $80 \times 100$ model grids), 40 vertical levels, and 4 soil layers, covering almost all the East Asian monsoon and India monsoon source area. The nested domain was centered at $27.828^{\circ} \mathrm{N}, 104.638^{\circ} \mathrm{E}$, with $20 \mathrm{~km}$ spatial resolution (about $94 \times 97$ model grids), 40 vertical levels, and 4 soil layers. The integral time step was set to $180 \mathrm{~s}$ for both domains.

In addition, the performance of the model was evaluated by conducting a validation test with the 2013 IGBP MODIS_MCD12Q1 LUCC data from 2013-06-01 00:00:00 to 2013-06-30 23:00:00. The simulation results of temperature and precipitation were interpolated to 120 meteorological stations by kriging method and the CORRCOEF and RMSE between the simulation results and the measured data were analyzed. The results are illustrated in Fig. 3, showing that the simulation of temperature in Southwest China by WRF was better than that of precipitation. As for temperature, the data of 110 stations among 120 meteorological stations had a CORRCOEF greater than 0.5 , occupied $92 \%$. And 108 among 120 meteorological stations had a RMSE lower than 5, occupied $90 \%$. The areas with worse simulation performance were located in Western Sichuan Plateau, Sichuan basin, and the west of Yunnan because it was inaccurate in simulating temperature on the hilltop. As for precipitation, only 12 among 120 meteorological stations had a CORRCOEF greater than 0.5, and the CORRCOEF of 44 meteorological stations was greater than 0.3. The RMSE of precipitation was a little unsatisfactory, especially in Guangxi and Guizhou, indicating that the WRF needed to be improved in simulating precipitation under broken surface and the land with great difference in topography.

\section{Results}

\subsection{The temperature change}

Comparing the mean $2 \mathrm{~m}$ air temperature in summer between Exp1 and Exp3 (Fig. 4a), the most significant increase occurred in the urban areas of Sichuan and Chungking provinces and the south coastal areas of Guangxi Province (even more than $3{ }^{\circ} \mathrm{C}$ ) due to the rapid urbanization during the 21 years. The most obvious decreasing areas were from Yunnan to the east Sichuan and Chungking about $0.5^{\circ} \mathrm{C}$ to $1.5^{\circ} \mathrm{C}\left(23^{\circ} \sim 33^{\circ}\right.$ $\mathrm{N}, 98^{\circ} \sim 108^{\circ}$ E). In Fig. $4 \mathrm{~b}$, the averaged summer $2 \mathrm{~m}$ air temperature difference between Exp2 and Exp3 had the same increase and decrease of $0.5^{\circ} \mathrm{C}$, indicating a smaller change compared with that between Exp1 and Exp3. The most significant cooling was also in east Sichuan and Chungking, while with a warming over the remaining regions, which indicated the decreasing temperature where the exposure rocks land cover transformed to the forest.

\subsubsection{The effect of radiation on temperature}

The simulation results of summer mean surface albedo, net shortwave radiation, net longwave radiation, and net radiation in 1993, 2003, and 2013 are illustrated in Fig. 5. The temperature change under improving KRD could be partly explained from the view of radiation balance. The KRD variation led to the changing of the surface albedo. The decrease/increase of surface albedo caused the increase/decrease of net shortwave radiation through the absorption of shortwave on the land surface and the release of longwave. The difference of net shortwave radiation and the ground effective radiation was defined as the net radiation, which could influence the surface temperature directly based on the Stephen Bolzmann's law.

As shown in Fig. 5a, the surface albedo decreased from 1993 to 2013 in most areas of Sichuan Basin and Yunnan by lower than -0.03 , and the south Guangxi by lower than -0.09 because of the improving KRD. The surface albedo showed an increase by $0.06 \sim 0.09$ in $22.9^{\circ} \sim 28.8^{\circ} \mathrm{N}, 105.2^{\circ} \sim 109.5^{\circ} \mathrm{E}$ where

Table 2 The parameterization schemes

\begin{tabular}{|c|c|c|c|c|c|}
\hline & \multicolumn{2}{|l|}{ Extent } & Resolution $/ \mathrm{km}$ & Planetary boundary layer & Land surface \\
\hline Layer 1 & \multicolumn{2}{|c|}{$9.5^{\circ} \mathrm{N} \sim 50.14^{\circ} \mathrm{N}, 70.55^{\circ} \mathrm{E} \sim 130.95^{\circ} \mathrm{E}$} & $60 \mathrm{~km}$ & YSU & NOAH \\
\hline \multirow[t]{2}{*}{ Layer 2} & \multicolumn{2}{|c|}{$19.52^{\circ} \mathrm{N} \sim 35.74^{\circ} \mathrm{N}, 95.04^{\circ} \mathrm{E} \sim 114.46^{\circ} \mathrm{E}$} & $20 \mathrm{~km}$ & YSU & NOAH \\
\hline & Surface layer & Cumulus & Microphysics & Shortwave radiation & Longwave radiation \\
\hline Layer 1 & Monin-Obukhov & Kain-Fritsch & WSM3 & Dudhia & RRTM \\
\hline Layer 2 & Monin-Obukhov & Kain-Fritsch & WSM3 & Dudhia & RRTM \\
\hline
\end{tabular}



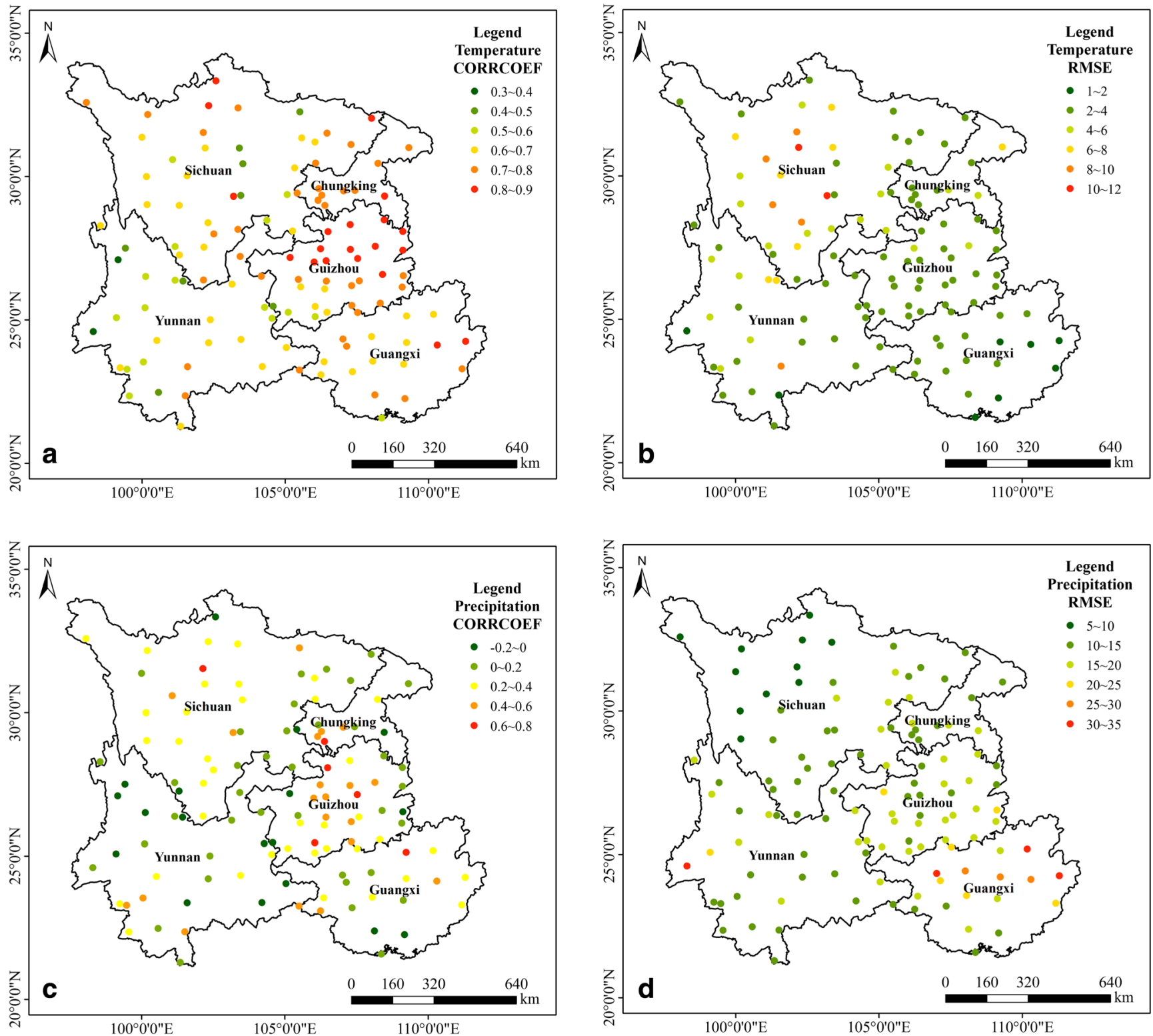

Fig. 3 The CORRCOEF and RMSE between the simulation results and the measured value. a The CORRCOEF of temperature. $\mathbf{b}$ The RMSE of temperature. $\mathbf{c}$ The CORRCOEF of precipitation. $\mathbf{d}$ The RMSE of precipitation

the limestone exposed. To the radiation processes, the most obvious increase of net shortwave radiation between Exp1 and Exp3 was up to $30 \mathrm{~W} / \mathrm{m}^{2}$ in the south of Guangxi, and it was decreased by $-20 \sim-30 \mathrm{~W} / \mathrm{m}^{2}$ in $23.8^{\circ} \sim 28.9^{\circ} \mathrm{N}, 105.4^{\circ} \sim 109.5^{\circ}$ E (Fig. 5c). The most decreased net longwave radiation was in the urban areas of Sichuan and Chungking provinces and the south coastal areas in Guangxi Province in excess of $20 \mathrm{~W} / \mathrm{m}^{2}$. Moreover, the net longwave radiation mixed changes in the south of the Southwest China. It decreased by $0 \sim-10 \mathrm{~W} / \mathrm{m}^{2}$ in the northwest of Sichuan and increased in the other areas (Fig. $5 \mathrm{e}$ ). To the net radiation (Fig. $5 \mathrm{~g}$ ), it mainly increased in the south of Guangxi by about $30 \mathrm{~W} / \mathrm{m}^{2}$ and the northeast and south of Yunnan by 10 20 W/m $/ \mathrm{m}^{2}$. The most decreased region of the net radiation was distributed in $22.6^{\circ} \sim 28.9^{\circ} \mathrm{N}, 103.8^{\circ} \sim 109.5^{\circ} \mathrm{E}$ $\left(-10 \sim-40 \mathrm{~W} / \mathrm{m}^{2}\right)$, and the urban areas in Sichuan and Chungking were lower than $-50 \mathrm{~W} / \mathrm{m}^{2}$.

Meanwhile, we also got the same results from the Exp2 and Exp3. Figure 5b shows that in Exp3, it had lower albedo compared with Exp2 by $-0.03 \sim-0.12$ in the south edge and central of Guangxi and the southwest edge of Yunnan. The increasing surface albedo was in the other areas by $0 \sim 0.03$. The decreasing net longwave radiation from 2003 to 2013 was located in the west of the Southwest China (Fig. 5d). However, the net shortwave radiation in Fig. $5 \mathrm{f}$ has different distribution with albedo in Fig. 5b in comparison of that in Fig. $5 \mathrm{a}$, e. The increased net radiation was mostly distributed in the east of the Southwest China and especially in Guangxi by more than $10 \mathrm{~W} / \mathrm{m}^{2}$ (Fig. 5 h). 


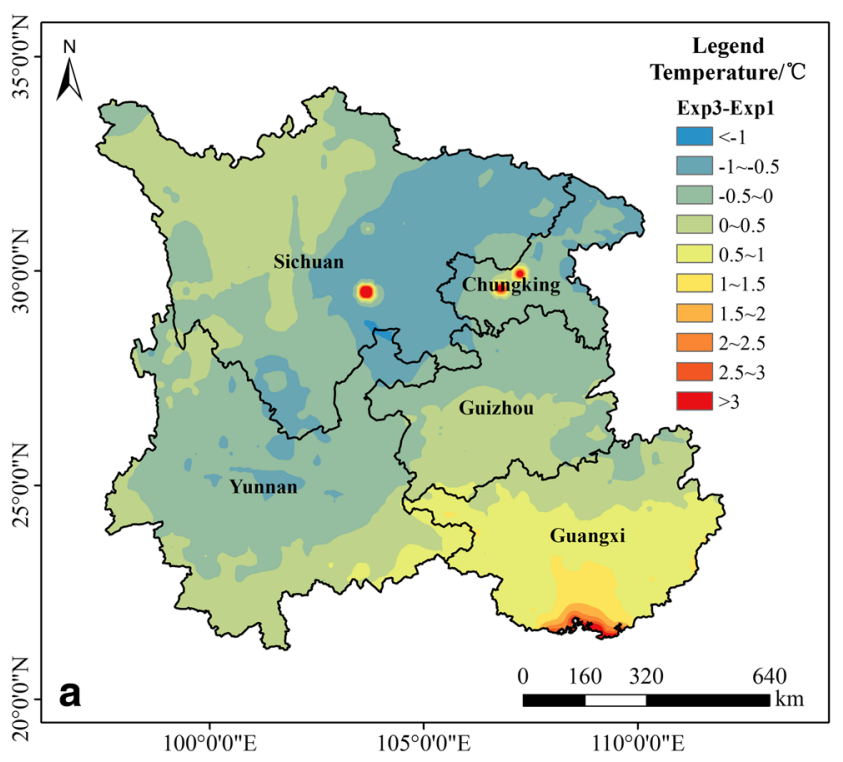

Fig. 4 The temperature difference. a Exp3-Exp1. b Exp3-Exp2

\subsubsection{The effect of heat flux on temperature}

According to the sensible heat flux difference between Exp1 and Exp3 in Fig. 6a, the most increased areas were in the southeast of Guangxi up to $20 \mathrm{~W} / \mathrm{m}^{2}$. The decreased latent heat flux was in the west Sichuan and in the magnitude of $22.1^{\circ} \sim 29.2^{\circ} \mathrm{N}, 102.3^{\circ} \sim 109.5^{\circ} \mathrm{E}$ by $0 \sim 20 \mathrm{~W} / \mathrm{m}^{2}$ (Fig. 6c). The local maximum increasing latent heat flux reached $20 \sim 40 \mathrm{~W} / \mathrm{m}^{2}$ in the northeast of Yunnan. By comparing the sensible heat flux in Exp2 and Exp3 in Fig. 6b, it decreased by $0 \sim-20 \mathrm{~W} / \mathrm{m}^{2}$ in Chungking and Sichuan, and it increased in Guangxi and Yunnan. In Fig. 6d, the most increased latent heat flux from 2003 to 2013 was exceeding $40 \mathrm{~W} / \mathrm{m}^{2}$ and distributed in Yunnan and south of Sichuan. However, the most decreased latent heat flux was lower than $-20 \mathrm{~W} / \mathrm{m}^{2}$ and was among Guangxi, the east of Sichuan, and the west of Chungking.

\subsection{The precipitation change and the effect of atmospheric circulation}

The summer precipitation difference in Fig. 7a, b has the similar spatial distribution, while the change was much larger between Exp1 and Exp3 than that between Exp2 and Exp3. The difference of precipitation distributed more dispersed than the temperature difference, varying among regions. The simulated positive difference in Fig. 7a was mainly located around southwest Yunnan up to $300 \mathrm{~mm}$ and some areas in Sichuan by more than $100 \mathrm{~mm}$. The simulated precipitation showed a decrease from 1993 to 2013 in the south of Yunnan lower than $200 \mathrm{~mm}$ and around $33^{\circ} \mathrm{N}, 104^{\circ} \mathrm{E}$ lower than $300 \mathrm{~mm}$. Meanwhile, the precipitation difference between Exp2 and Exp3 (Fig. 7b) showed negative in south Guangxi, the west Sichuan, and Yunnan. A decrease up to $100 \mathrm{~mm}$ was in $27.2^{\circ} \sim 33.3^{\circ} \mathrm{N}$,

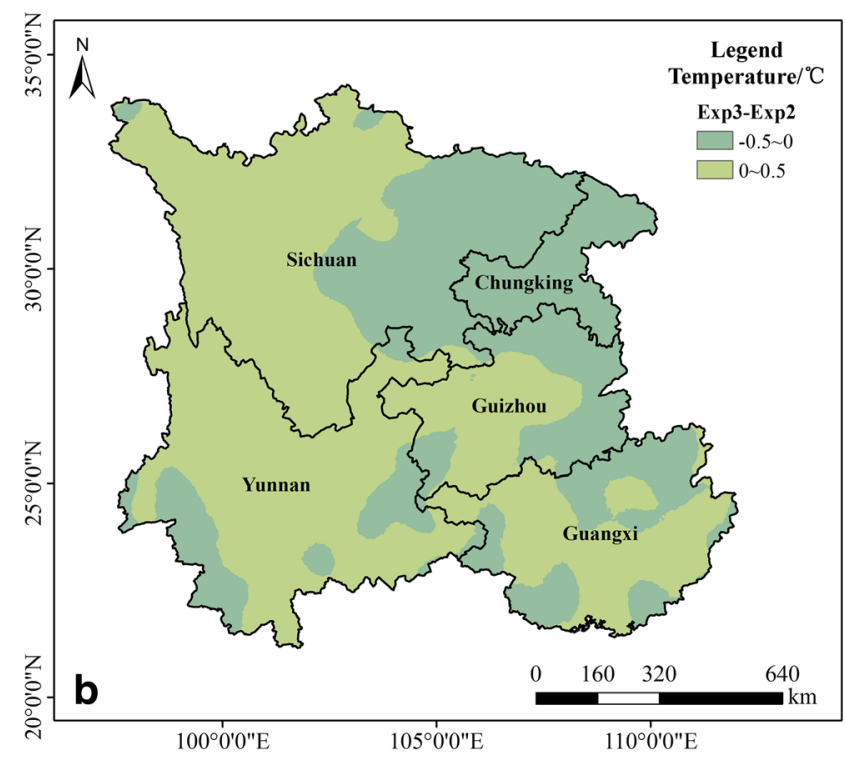

$100.6^{\circ} \sim 105.0^{\circ} \mathrm{E}$ and the southwest edge of Yunnan, while an increase up to $100 \mathrm{~mm}$ was located in some area of east Sichuan.

The main airflow which brought moisture to the Southwest China was the southwest monsoon from Bay of Bengal and the subtropical high. The KRD variation could affect the reaction between the land surface and atmosphere, which could further influence the vertical layer atmospheric circulation and cause the precipitation changing. Through analyzing the wind field and pressure field of atmospheric circulation such as the subtropical high at upper levels at $500 \mathrm{hPa}$ and the monsoon layer at $700 \mathrm{hPa}$, we tried to investigate the biogeophysical mechanisms of precipitation changing under improving KRD. As shown in Fig. 8a, the wind speed at $500 \mathrm{hPa}$ decreased in Guangxi, the south Yunnan, and the east Guizhou. However, the wind speed increased in the north Yunnan, the west Guizhou, Chungking, and the east Sichuan where the westerly wind vector component in Exp3 was larger than that in Exp1. Furthermore, the changing of the high altitude weather system at $500 \mathrm{hPa}$ could lead to the changing of the southwest monsoon at $700 \mathrm{hPa}$. From Fig. 8c, the southerly component at $700 \mathrm{hPa}$ was larger in 2013 than that in 1993, located in the north of Yunnan and the southeast of Sichuan, while the westerly component was smaller in Guizhou. The wind speed increased in Guangxi but decreased in Chungking and the northeast of Sichuan at $700 \mathrm{hPa}$. By comparing the precipitation distribution of Exp2 and Exp3, the results shown in Fig. 8b, d revealed the same mechanisms of precipitation change. In Fig. $8 \mathrm{~b}$, wind speed decreased in the south and northwest of Yunnan, the north of Chungking and Sichuan but increased in the south Chungking, Guizhou, and the northwest and southeast of Yunnan from 2003 to 2013 at $500 \mathrm{hPa}$. At $700 \mathrm{hPa}$ (Fig. 8d), the southerly component increased in the northwest of Yunan and the wind speed decreased mainly in Guizhou and the northeast of Yunnan. 

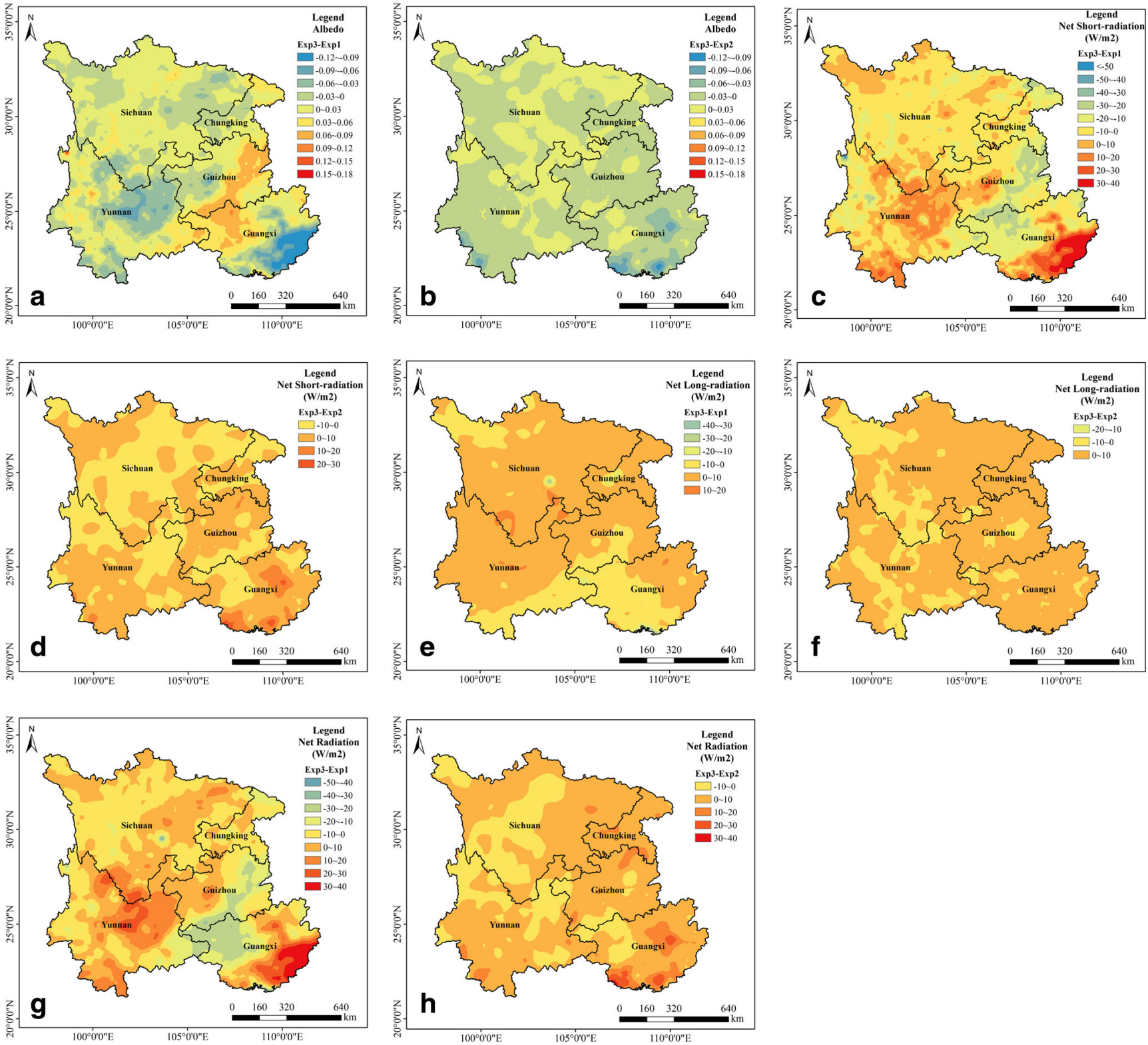

Fig. 5 The surface albedo difference $(\mathbf{a}, \mathbf{b})$. The net shortwave radiation difference $(\mathbf{c}, \mathbf{d})$. The net longwave radiation difference $(\mathbf{e}, \mathbf{f})$. The net radiation difference $(\mathbf{g}, \mathbf{h})$

Figure $8 \mathrm{e}, \mathrm{f}$ showed the difference of the summer mean geopotential height (GHT) at $500 \mathrm{hPa}$ and the upward moisture flux at the surface (QFX) between the three simulation experiments. Compared with Exp1 in Fig. 8e, the GHT of subtropical high $(5880 \mathrm{~m})$ moved to the westward and even all the isopotential heights moved to the northwest in Exp3. However, the subtropical high did not have much change in Fig. $8 \mathrm{f}$ except for the isopotential height of $5845 \mathrm{~m}$ and $5850 \mathrm{~m}$ which slightly moved to the northwest, probably because the terrestrial ecosystem had less change between 2003 and 2013 than that between 1993 and 2013. As for QFX, it increased from 1993 to 2013 by $0.003 \sim 0.012 \mathrm{~kg} /\left(\mathrm{m}^{2} \mathrm{~s}\right)$, located in the north of Yunnan, the south edge and central Sichuan, and west Guangxi because enhanced southwest monsoon according to Fig. 8c, e. The most decreased QFX by more than $0.003 \mathrm{~kg} /\left(\mathrm{m}^{2} \mathrm{~s}\right)$ was in the magnitude of $22.1^{\circ} \sim 27.5^{\circ}$ $\mathrm{N}, 102.5^{\circ} \sim 109.5^{\circ} \mathrm{E}$ due to the influence of easterly sinking airflow. In Fig. 8f, the decreasing region of QFX between Exp2 and Exp3 was mainly located in the west of southwest China. The increasing QFX was in east Sichuan, Chungking, the south edge of Guangxi, the central Guangxi, and some regions in south Yunnan by $0.003 \sim 0.009 \mathrm{~kg} /\left(\mathrm{m}^{2} \mathrm{~s}\right)$.

\section{Discussion}

In this study, we designed three groups of independent simulation experiments to investigate the KRD effects on regional 

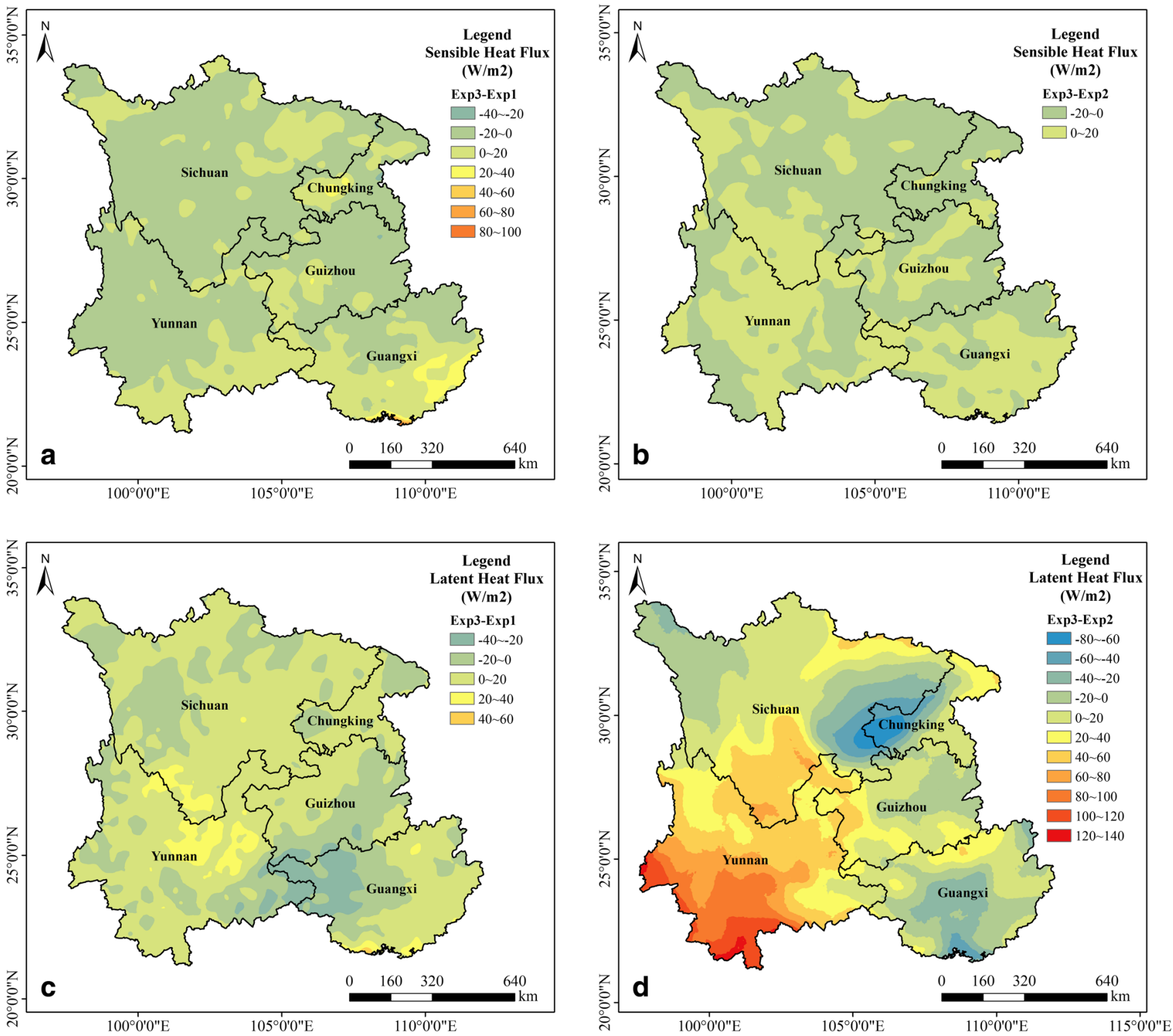

Fig. 6 The sensible heat flux difference $(\mathbf{a}, \mathbf{b})$. The latent heat flux difference $(\mathbf{c}, \mathbf{d})$

climate in the Southwest China based on WRF static LUCC data in 1993, 2003, and 2013. The KRD had been improved from 1993 to 2013 and the recovering areas were mainly located in the south of Guangxi, southwest Yunnan, Chungking, and east Sichuan by spatio-temporal analysis. Therefore, we used the simulation results under an improving trend of KRD to study the KRD's regional climate effect inversely. By comparing the simulation results, the biogeophysical processes of temperature change were verified. The improving KRD led to the decreasing surface albedo, the increasing net shortwave radiation, and the decreasing net longwave radiation so that the net radiation increased. And the same results could be found in the previous studies that the deforestation could increase surface albedo and decrease net radiation to cool the surface (Lejeune et al. 2015). However, the surface cooling caused by increasing net radiation might be enhanced or weakened by non-radiative processes (Boisier et al. 2012), because the change of surface condition could also alter the turbulence transmission between land and atmosphere to influence the surface energy and water balance (Davin and Nobletducoudré 2010; Gibbard et al. 2005; Davin et al. 2007; Rigden and Li 2017). In this study, the sensible heat flux extremely decreased and the latent heat flux increased where the KRD condition had improved excepting for the south of Guangxi Province due to the effect of land-sea difference principal and the urbanization in the coastal area. As a consequence, the $2 \mathrm{~m}$ air temperature decreased by $0 \sim-1{ }^{\circ} \mathrm{C}$ in most areas because the high evapotranspiration made the latent heat replacing the sensible heat (Ban-Weiss et al. 2011; Gálos et al. 2011), which indicated that the evapotranspiration cooling effect dominated the $2 \mathrm{~m}$ air temperature change in Southwest China. The similar results were also found in Gao 


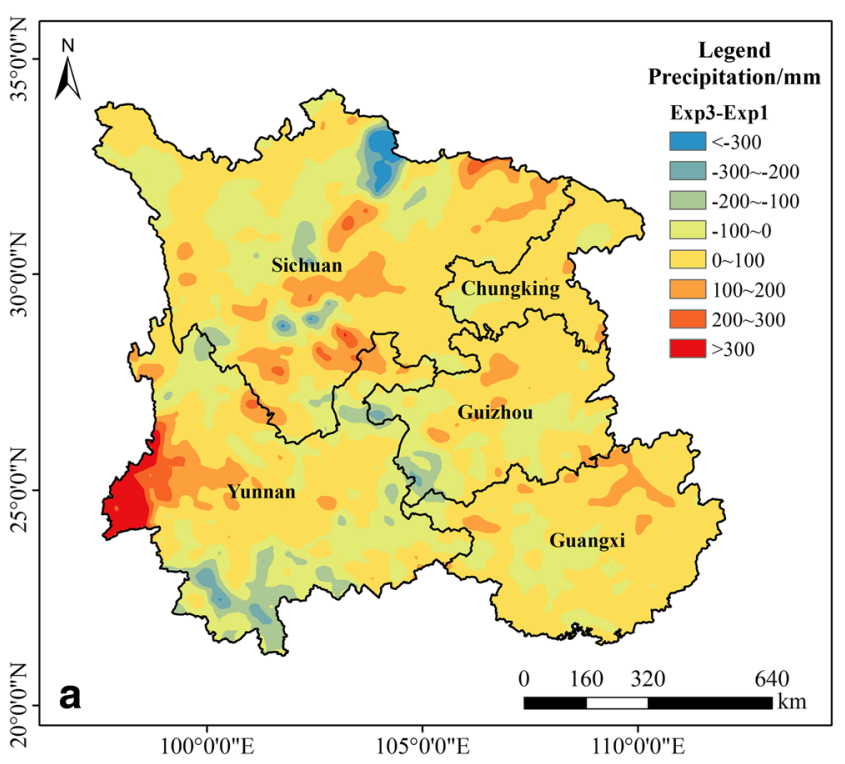

Fig. 7 The precipitation difference. a Exp3-Exp1. b Exp3-Exp2

et al.'s (Gao et al. 2013; Gao and Wu 2014) research that the land degradation over the Guizhou Karst Plateau increased the surface temperature through the net radiation and evaporation reducing. And in some areas of the USA, northern Europe, and Siberia, the forest cover gains could also lead to an annual cooling by various non-radiative mechanisms (Bright et al. 2017).

Moreover, the spatial gradient of surface heat flux changing can also effect the large-scale circulations (Renato et al. 2008).

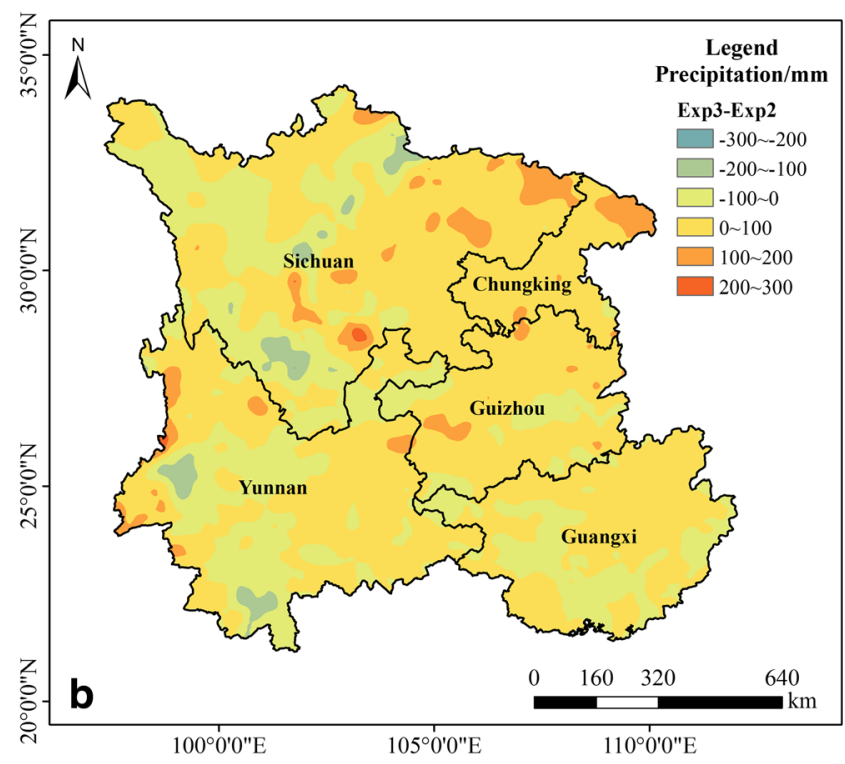

The KRD in Southwest China had been improved from 1993 to 2013 and the surface changing signal led to the change of temperature field and pressure field. These physical signals transferred to the upper troposphere through the atmosphere vertical convection, which could cause the GHT of subtropical high $(5880 \mathrm{~m})$ moving to the west so that the subtropical high was strengthened and westerly extended. Thus, the easterly sinking airflow in the south of subtropical high suppressed the generation of convection, manifesting as the reduction of
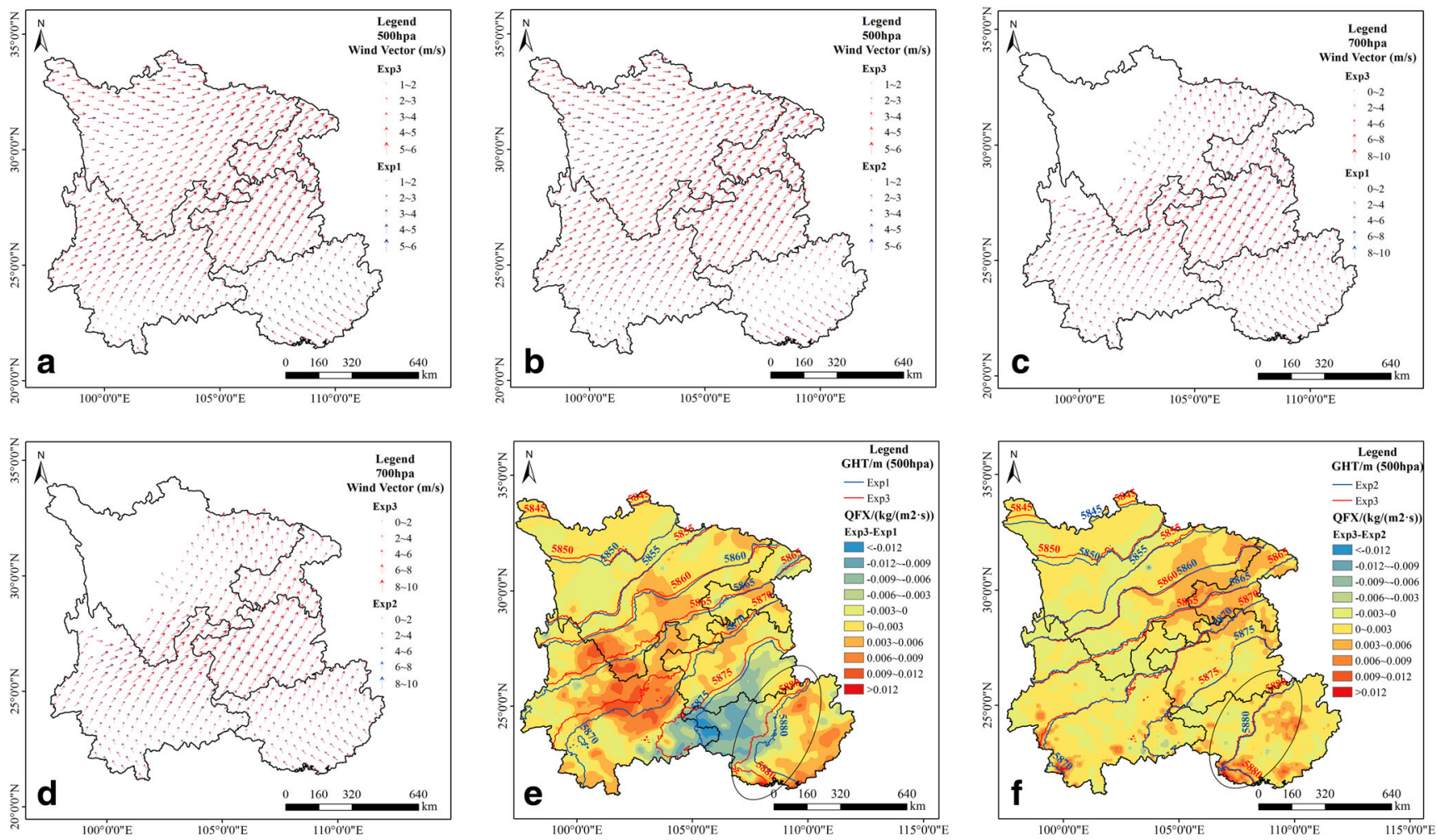

Fig. 8 The wind vector at $500 \mathrm{hPa}(\mathbf{a}, \mathbf{b})$. The wind vector at $700 \mathrm{hPa}(\mathbf{c}, \mathbf{d})$. The QFX difference and GHT at $500 \mathrm{hPa}(\mathbf{e}, \mathbf{f})$ 
QFX in central Guangxi. Meanwhile, the precipitation was also decreasing in central Guangxi based on that the QFX had a direct impact on precipitation change (Pitman and Lorenz 2016). In contrast, the southwest monsoon could be strengthened because the east wind imported in the south of subtropical high, which would cause the increasing precipitation in the west of Yunnan with the increasing QFX. The similar results could also be found in the study by Gao et al. (2013) that the southwest monsoon flow was weakened due to the interaction of land and atmosphere resulting from land degradation. Besides, the strengthening of the southwest jet made the increasing precipitation because the passageway of the southwest monsoon was in southwest Yunnan. When the southwest monsoon arrived at the northeast of Sichuan, the airflow's ability of carrying water vapor weakened and the wind speed slowed down so that the precipitation decreased in that area.

Although our study solved part of the biogeophysical processes of energy, heat flux, and moisture transferring between land surface and atmosphere under the real LUCC condition, the coarse spatial resolution and uncertainties were still inevitable to study regional climate change. For example, the parameterization schemes we chose had a relatively bad simulation performance of precipitation in Southwest China due to the complex land surface conditions. And in the biogeophysical processes explaination part, the local precipitation change was affected by even more factors not only by the $500 \mathrm{hPa}$ and $700 \mathrm{hPa}$ wind vector and QFX change. Besides, we used the biogeophysical processes of climate change under an improving trend of KRD to study the KRD climate effect in return. In the future, we would better build a realistic LUCC condition of different grades of land degradation to explore the interactions between KRD surface and atmosphere.

\section{Conclusions}

The main objective of this paper was to investigate the biogeophysical impact of temperature and precipitation change under KRD change. It could be concluded that:

(1) The KRD in Southwest China had been recovering from 1993 to 2013, and the trend of deeply severely KRD had been controlled.

(2) The temperature decreased where the KRD was improved because the contribution of the upward latent heat flux contributed greater than the upward sensible heat flux and the increasing net radiation.

(3) The improving KRD caused the GHT of subtropical high $(5880 \mathrm{~m}$ at $500 \mathrm{hPa}$ ) moving to west so that the subtropical high and southwest monsoon were strengthened, which made the increasing precipitation where the QFX increased.
Acknowledgments The authors would like to specially thank the Environmental and Ecological Science Data Center for West China, National Natural Science Foundation of China and International Scientific \& Technical Data Mirror Site, Computer Network Information Center, Chinese Academy of Sciences for the provision of NDVI data. We also gratefully acknowledge the NASA for LUCC data and CMDC for V3.0 temperature and precipitation data.

Funding information This work was supported by the Natural Science Foundation of China (41571040), National Key Research and Development Program of China (2016YFC052300), and the open funding supported by LASG, CAS.

Open Access This article is distributed under the terms of the Creative Commons Attribution 4.0 International License (http:// creativecommons.org/licenses/by/4.0/), which permits unrestricted use, distribution, and reproduction in any medium, provided you give appropriate credit to the original author(s) and the source, provide a link to the Creative Commons license, and indicate if changes were made.

\section{References}

Ban-Weiss GA, Bala G, Cao L, Pongratz J, Caldeira K (2011) Climate forcing and response to idealized changes in surface latent and sensible heat. Environ Res Lett 6(3):034032. https://doi.org/10.1088/ 1748-9326/6/3/034032

Betts AK, Ball JH, Beljaars ACM, Miller MJ, Viterbo PA (1996) The land surface-atmosphere interaction: a review based on observational and global modeling perspectives. J Geophys Res 101(D3):7209-7225

Boisier JP, Noblet-Ducoudré ND, Pitman AJ et al (2012) Attributing the impacts of land-cover changes in temperate regions on surface temperature and heat fluxes to specific causes: results from the first LUCID set of simulations. J Geophys Res 117:D12116. https:// doi.org/10.1029/2011JD017106

Bonan GB (2008) Forests and climate change: forcings, feedbacks, and the climate benefits of forests. Science 320(5882):1444-1449. https://doi.org/10.1126/science.1155121

Bright RM, Davin E, O'Halloran T, Pongratz J, Zhao K, Cescatti A (2017) Local temperature response to land cover and management change driven by non-radiative processes. Nat Clim Chang 7(4): 296-302. https://doi.org/10.1038/NCLIMATE3250

Cao Q, Yu D, Georgescu M, Han Z, Wu J (2015) Impacts of land use and land cover change on regional climate: a case study in the agropastoral transitional zone of China. Environ Res Lett 10(12): 124025. https://doi.org/10.1088/1748-9326/10/12/124025

Chen L, Dirmeyer PA (2016) Adapting observationally based metrics of biogeophysical feedbacks from land cover/land use change to climate modeling. Environ Res Lett 11(3):034002. https://doi.org/10. 1088/1748-9326/11/3/034002

Davin EL, Nobletducoudré ND (2010) Climatic impact of global-scale deforestation: radiative versus nonradiative processes. J Clim 23(1): 97-112. https://doi.org/10.1175/2009JCLI3102.1

Davin EL, Noblet-Ducoudré ND, Friedlingstein P (2007) Impact of land cover change on surface climate: relevance of the radiative forcing concept. Geophys Res Lett 34:L13702. https://doi.org/10.1029/ 2007GL029678

Feddema JJ, Oleson KW, Bonan GB, Meams LO, Buja LE, Meehl GA, Washington WM (2005) The importance of land-cover change in simulating future climates. Science 310(5754):1674-1678. https:// doi.org/10.1126/science.1118160 
Gálos B, Mátyás C, Jacob D (2011) Regional characteristics of climate change altering effects of afforestation. Environ Res Lett 6(4): 044010. https://doi.org/10.1088/1748-9326/6/4/044010

Gao J, Wu S (2014) Simulated effects of land cover conversion on the surface energy budget in the southwest of China. Energies 7(3): 1251-1264. https://doi.org/10.3390/en7031251

Gao J, Xue Y, Wu S (2013) Potential impacts on regional climate due to land degradation in the Guizhou Karst Plateau of China. Environ Res Lett 8(4):004037(9pp). https://doi.org/10.1088/1748-9326/8/4/ 044037

Ghimire B, Williams CA, Masek J, Gao F, Wang Z, Schaaf C, He T (2014) Global albedo change and radiative cooling from anthropogenic land cover change, 1700 to 2005 based on MODIS, land use harmonization, radiative kernels, and reanalysis. Geophys Res Lett 41(24):9087-9096. https://doi.org/10.1002/2014GL061671

Gibbard S, Caldeira K, Bala G, Phillips TJ, Wickett M (2005) Climate effects of global land cover change. Geophys Res Lett 32(23): L23705. https://doi.org/10.1029/2005GL024550

Hirsch AL, Pitman AJ, Seneviratne SI, Evans JP, Haverd V (2014) Summertime maximum and minimum temperature coupling asymmetry over Australia determined using WRF. Geophys Res Lett 41(5):1546-1552. https://doi.org/10.1002/2013GL059055

Jiang Y, Li L, Groves C et al (2009) Relationships between rocky desertification and spatial pattern of land use in typical karst area, Southwest China. Environ Earth Sci 59(4):881-302. https://doi. org/10.1038/NCLIMATE3250

Jiang Z, Lian Y, Qin X (2014) Rocky desertification in Southwest China: impacts, causes, and restoration. Earth Sci Rev 132(3):1-12. https:// doi.org/10.1016/j.earscirev.2014.01.005

Kala J, Lyons TJ, Nair US (2011) Numerical simulations of the impacts of land-cover change on cold fronts in South-west Western Australia. Bound-Layer Meteorol 138(1):121-138

Lejeune Q, Davin E, Guillod B, Seneviratne SI (2015) Influence of Amazonian deforestation on the future evolution of regional surface fluxes, circulation, surface temperature and precipitation. Clim Dynam 44(9-10):2769-2786. https://doi.org/10.1007/s00382-0142203-8

Li Y, Shao J, Hua Y, Bai X (2009) The relations between land use and karst rocky desertification in a typical karst area, China. Environ Geol 57(3):621-627. https://doi.org/10.1007/s00254-008-1331-z

Li Y, Zhao M, Motesharrei S, Mu Q, Kalnay E, Li S (2015) Local cooling and warming effects of forests based on satellite observations. Nat Commun 6:6603. https://doi.org/10.1038/ncomms7603

Lian Y, You J, Lin K, Jiang Z, Zhang C, Qin X (2014) Characteristics of climate change in Southwest China karst region and their potential environmental impacts. Environ Earth Sci 74(2):937-944. https:// doi.org/10.1007/s12665-014-3847-8

Lu H, Qin W, Li Y, Zhou X, Liao X (2015) Analysis on climate variation characteristics of rocky desertification region of Guangxi in recent 40 years $[\mathrm{J}]$. Journal of Meteorological Research and Application 36(1):6-10 (in Chinese)

Pielke RA Sr, Pitman A, Niyogi D et al (2011) Land use/land cover changes and climate: modeling analysis and observational evidence. Wires Clim Change 2(6):828-850. https://doi.org/10.1002/wcc.144
Pinzón JE, Brown ME, Tucker CJ (2005) EMD correction of orbital drift artifacts in satellite data stream. Hilbert-Huang transform and its applications (2nd edition) 167-186. doi https://doi.org/10.1142/ 9789812703347_0008

Pitman AJ, Lorenz R (2016) Scale dependence of the simulated impact of Amazonian deforestation on regional climate. Environ Res Lett 11(9):094025. https://doi.org/10.1088/1748-9326/11/9/094025

Pitman AJ, Narisma GT, Pielke RA Sr, Holbrook NJ (2004) Impact of land cover change on the climate of Southwest Western Australia. J Geophys Res 109:D18109. https://doi.org/10.1029/2003JD004347

Pitman AJ, Nobletducoudré ND, Avila FB et al (2012) Effects of land cover change on temperature and rainfall extremes in multi-model ensemble simulations. Earth Syst Dynam 3(2):213-231. https://doi. org/10.5194/esd-3-213-2012

Pongratz J, Bounoua L, Defries RS, Morton DC, Anderson LO, Mauser W, Kllnk CA (2006) The impact of land cover change on surface energy and water balance in Mato Grosso, Brazil [J]. Earth Interact 10(1):1-302. https://doi.org/10.1038/NCLIMATE3250

Renato RDS, Werth D, Avissar R (2008) Regional impacts of future landcover changes on the Amazon Basin wet-season climate. J Clim 21(6):1153-1170. https://doi.org/10.1175/2007JCLI1304.1

Rigden AJ, Li D (2017) Attribution of surface temperature anomalies induced by land use and land cover changes. Geophys Res Lett 44(13):6814-6822. https://doi.org/10.1002/2017GL073811

Seneviratne SI, Lüthi D, Litschi M, Schär C (2006) Land-atmosphere coupling and climate change in Europe. Nature 443:205-209. https://doi.org/10.1038/nature05095

State Forestry Administration P.R. China (2012) China Rocky Desertification Situation Bulletin (in Chinese)

Tucker CJ, Pinzon JE, Brown ME (2004) Global inventory modeling and mapping studies, NA94apr15b.n11-VIg, 2.0, Global Land Cover Facility, University of Maryland, College Park, Maryland, 04/15/1994

Vygodskaya NN, Groisman PY, Tchebakova NM, Kurbatova JA, Panfyorov O, Parfenova EI, Sogachev AF (2007) Ecosystems and climate interactions in the boreal zone of northern Eurasia. Environ Res Lett 2(4):45033(7pp. https://doi.org/10.1088/1748-9326/2/4/ 045033

Wang Y, Feng J, Gao H (2014) Numerical simulation of the impact of land cover change on regional climate in China. Theor Appl Climatol 115(1-2):141-152. https://doi.org/10.1007/s00704-0130879-Z

Yan X, Cai YL (2015) Multi-scale anthropogenic driving forces of karst rocky desertification in Southwest China. Land Degrad Dev 26(2): 193-200 0.1002/ldr.2209

Ying B, Xiao S, Xiong K, Chen Q, Luo J (2012) The distribution characteristics of rocky desertification and land use/land cover in karst gorge area. Adv Mater Res 518-523(2):4661-4669. https://doi.org/ 10.4028/www.scientific.net/AMR.518-523.4661

Ying B, Xiao S, Xiong K, Chen Q, Luo J (2014) Comparative studies of the distribution characteristics of rocky desertification and land use/ land cover classes in typical areas of Guizhou Province, China. [J]. Environ Earth Sci 71(2):631-645. https://doi.org/10.1007/s12665$013-2460-6$ 